\title{
Association between quantitative and qualitative image features of contrast-enhanced mammography and molecular subtypes of breast cancer
}

\author{
Simin Wang ${ }^{1,2 \#}$, Zhenxun Wang ${ }^{3 \#}$, Ruimin Li $^{1,2 \#}$, Chao You ${ }^{1,2}$, Ning Mao ${ }^{4}$, Tingting Jiang ${ }^{1,2}, Z^{2}$ hongyi Wang ${ }^{4}$, \\ Haizhu Xie ${ }^{4}$, Yajia Gu, \\ ${ }^{1}$ Department of Radiology, Fudan University Shanghai Cancer Center, Shanghai, China; ${ }^{2}$ Department of Oncology, Shanghai Medical College, \\ Fudan University, Shanghai, China; ${ }^{3}$ Amgen Inc., Thousand Oaks, CA, USA; ${ }^{4}$ Department of Radiology, Yantai Yuhuangding Hospital, Qingdao \\ University, Qingdao, China
}

Contributions: (I) Conception and design: S Wang, R Li; (II) Administrative support: None; (III) Provision of study materials or patients: None; (IV) Collection and assembly of data: S Wang, R Li; (V) Data analysis and interpretation: Z Wang; (VI) Manuscript writing: All authors; (VII) Final approval of manuscript: All authors.

\#These authors contributed equally to this work.

Correspondence to: Yajia Gu. Department of Oncology, Shanghai Medical College, Fudan University, 270 Dongan Road, Shanghai 200032, China. Email: guyajia@126.com.

Background: The molecular subtype of breast cancer is one of the most important factors affecting patient prognosis. The study aimed to analyze the association between quantitative and qualitative features of contrast-enhanced mammography (CEM) images and breast cancer molecular subtypes.

Methods: This retrospective double-center study included women who underwent CEM between November 2017 and April 2020. Each patient had at least 1 malignant lesion confirmed by pathology. The CEM images were evaluated by 2 radiologists to obtain quantitative and qualitative image features. The molecular subtypes were studied as dichotomous outcomes, including luminal versus non-luminal, human epidermal growth factor receptor (HER2)-enriched versus non-HER2-enriched, and triple-negative breast cancer (TNBC) versus non-TNBC subtypes. The association between the image features and molecular subtypes was analyzed by multivariate logistic regression, with odds ratios (ORs) and $95 \%$ confidence intervals (CIs) provided.

Results: A total of 151 patients with 160 malignant lesions were included in the study. For quantitative features, a higher standard deviation of lesion density was associated with non-luminal $(\mathrm{OR}=0.88,95 \%$ CI: 0.81 to $0.96, \mathrm{P}=0.004)$ and HER2-enriched breast cancers ( $\mathrm{OR}=1.16,95 \% \mathrm{CI}$ : 1.04 to $1.28, \mathrm{P}=0.006)$. The relative degree of enhancement (RDE) and contrast-to-noise ratio (CNR) were not associated with molecular subtypes. However, a higher $\mathrm{CNR} /$ lesion size $(\mathrm{OR}=1.06,95 \% \mathrm{CI}: 1.01$ to $1.12, \mathrm{P}=0.012)$ was associated with luminal subtype cancers, and a higher $\mathrm{RDE} / \mathrm{lesion}$ size (OR $=0.94,95 \% \mathrm{CI}: 0.88$ to 1.00 , $\mathrm{P}=0.035$ ) or a higher $\mathrm{CNR} / \mathrm{lesion}$ size $(\mathrm{OR}=0.94$, 95\% CI: $0.88-1.00, \mathrm{P}=0.038)$ was associated with nonTNBCs. For qualitative features, the presence of calcification was associated with HER2-enriched breast cancers $(\mathrm{OR}=2.91,95 \% \mathrm{CI}: 1.10$ to $7.67, \mathrm{P}=0.031)$. The presence of architectural distortion was associated with luminal cancer $(\mathrm{OR}=14.50,95 \% \mathrm{CI}$ : 1.91 to $110.14, \mathrm{P}=0.010)$ and non-TNBC $(\mathrm{OR}=0.05,95 \% \mathrm{CI}$ : 0.00 to $0.43, \mathrm{P}=0.022$ ). Non-mass enhancement $(\mathrm{OR}=2.78,95 \% \mathrm{CI}: 1.08$ to $7.14, \mathrm{P}=0.033)$ was associated with HER2-enriched breast cancers. An association remained after adjustments for age, breast thickness, and breast density (all adjusted $\mathrm{P}<0.050$ ).

Conclusions: The quantitative and qualitative imaging features of CEM could contribute to distinguishing breast cancer molecular subtypes. 
Keywords: Contrast-enhanced mammography (CEM); breast cancer; molecular subtype; quantitative

Submitted Jun 06, 2021. Accepted for publication Sep 24, 2021.

doi: 10.21037/qims-21-589

View this article at: https://dx.doi.org/10.21037/qims-21-589

\section{Introduction}

Breast cancer is the most common cancer and the leading cause of cancer death in women (1). Several histopathological factors, such as tumor grade, molecular subtypes, and status of axillary lymph nodes, are crucial to decision-making in clinical treatment and are related to the prognosis of breast cancer $(2,3)$. The molecular subtype of breast cancer is one of the most important factors affecting the prognosis of patients. Therefore, it is important to identify the image features related to molecular subtypes that can reflect the underlying biological characteristics of the tumors.

Contrast-enhanced mammography (CEM) is an emerging breast imaging technique that combines conventional mammography and iodinated contrast material (4). It can demonstrate breast cancers by visualizing neovascularity similarly to breast magnetic resonance imaging (MRI) (5). Several studies have shown correlations between molecular subtypes and image features in breast MRI (6-9). As a result, we hypothesized that the imaging features of CEM may also be related to this prognostic factor.

For clinical application, a standard CEM consists of 2 sets of images, including a low-energy (LE) image, which is similar to conventional mammography $(10,11)$, and a dualenergy subtraction (DES) image, which can show contrastenhanced malignancies $(12,13)$. It can provide information regarding the degree of vascularization in addition to morphological information. Thus, various qualitative and quantitative, and image features can be obtained from the LE and DES images. Several studies have used CEM image features to differentiate between benign and malignant lesions (14-21), while others have explored the relationship between radiomic features of CEM and histopathological factors of breast cancer (22-25). However, few studies thus far have focused on the correlation between image features of CEM and prognostic factors of breast cancer.

Therefore, the study aimed to describe and discuss the association between qualitative and quantitative imaging features of CEM and different molecular subtypes of breast cancer. We present the following article in accordance with the MDAR checklist (available at https://dx.doi. org/10.21037/qims-21-589).

\section{Methods}

\section{Participants}

We retrospectively collected data from consecutive female patients who underwent CEM at Fudan University Shanghai Cancer Center and Yantai Yuhuangding Hospital between January 2019 and September 2020. The study was conducted in accordance with the Declaration of Helsinki (as revised in 2013). The study was approved by the Ethics Committee of each center (2006219-14; [2019]298), and individual consent for this retrospective analysis was waived.

The inclusion criteria were as follows: (I) aged 21 years or older; (II) referred for CEM by their breast surgeon; and (III) newly diagnosed breast cancers verified by histopathology. The indications for CEM in this study included (I) problem solving for inconclusive findings on screening mammography or ultrasound; (II) evaluation of symptomatic patients; and (III) preoperative assessment of disease extent. We excluded patients (I) with missing image data $(\mathrm{n}=12)$; (II) with poor image quality $(\mathrm{n}=9)$; and (III) with a history of breast surgery, breast radiotherapy, chemotherapy, or hormone treatment within 6 months before CEM ( $\mathrm{n}=11)$. Ultimately, 151 patients with 160 lesions were recruited for the study (Figure 1).

\section{CEM protocol}

The CEM was performed using the Senographe Essential mammography system (GE Healthcare, Buc, France). First, all participants received an intravenous injection of iohexol (350 mgI/mL, Beilu Pharmaceutical Co., Ltd., Beijing, China) at a dose of $1.5 \mathrm{~mL} / \mathrm{kg}$ and a rate of $3 \mathrm{~mL} / \mathrm{s}$. At $2 \mathrm{~min}$ after the start of the injection, the images were obtained in the order of craniocaudal (CC) and mediolateral oblique (MLO) views of the suspicious breast and CC and MLO views of the less suspicious breast. A pair of high- and low-energy exposures for each mammographic projection were consecutively performed, and a DES image was 


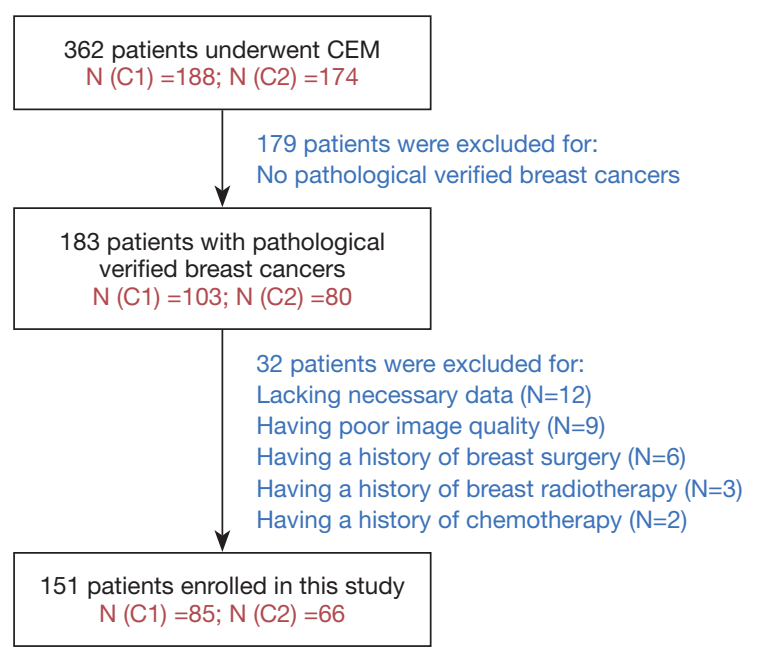

Figure 1 Patient inclusion and exclusion workflow. CEM, contrast-enhanced mammography.

generated automatically with the mammography unit. The total examination time did not exceed $10 \mathrm{~min}$.

\section{Quantitative and qualitative image features}

The CEM images were evaluated by 2 independent radiologists with 10 and 5 years of experience in breast imaging. Both radiologists were blinded to the clinical and histopathological information of the participants. In cases of discrepancy, the final decision was made in consensus.

There are currently no specific interpretation criteria for CEM images $(19,26)$. Therefore, the Breast Imaging Reporting and Data System (BI-RADS) lexicons for mammography and MRI were employed as references to evaluate the LE and DES images, respectively (27). For the LE images, lesion type [presence or absence of mass, calcification, architectural distortion (AD), or asymmetry] was recorded. The enhancement type (mass or non-mass enhancement) and enhancement degree (mild, moderate, or marked enhancement) were evaluated for the DES images. Furthermore, breast density (a, b, c, or d), degree of background parenchymal enhancement (minimal, mild, moderate, or marked), and breast thickness $(\mathrm{mm})$ were also extracted from CEM images, as these factors can reflect the demographic characteristics of the patients. The 3 factors were not included in the multivariate statistical analysis. Breast thickness was obtained from the CC view of the affected side of the breast.

For the quantitative assessment, we referred to the method of Rudnicki et al. (14). First, a circular region of interest (ROI) of approximately $1 \mathrm{~cm}^{2}$ (28) was manually placed over the most evident enhanced area within the lesion. Second, another ROI of $1 \mathrm{~cm}^{2}$ was placed in the most homogenous background area, avoiding the lesion, pectoral muscle, and artifact areas. Third, the mean density and standard deviation (SD) values of the lesion ROI and background ROI were recorded. Fourth, the relative degree of enhancement (RDE) and contrast-to-noise ratio (CNR) was calculated for each lesion as follows:

$$
\begin{aligned}
& R D E=\frac{D_{l}-D_{b}}{D_{b}} \times 100 \\
& C N R=\frac{D_{l}-D_{b}}{\sigma_{b}}
\end{aligned}
$$

Where $D_{l}$ represents the mean density value of the lesion ROI, $D_{b}$ represents the mean density value of the background ROI, and $\sigma_{b}$ represents the standard deviation value of the background ROI (29). The mean lesion density, $\mathrm{SD}$ of lesion density, RDE, and CNR values were extracted separately using CC and MLO view images, and the higher values were regarded as the final results (Figure 2). Since the DES images were projection images that overlap all the tumor thicknesses (30), the quantitative enhancement level of the lesions may be the result of the superposition of signal intensity in the direction of breast compression. Therefore, we calculated another 2 values, namely, RDE/ lesion size and CNR/lesion size, to reduce the impact of this overlap effect. The lesion sizes were measured by 2 radiologists independently on either CC or MLO views of DES images, depending on from which images the CNR and RDE values were calculated. The mean values of lesion sizes measured by 2 radiologists were calculated as the final lesion sizes. A summary of the qualitative and quantitative features interpreted and calculated from the CEM images is shown in the Table S1.

The intraclass correlation coefficient (ICC) was used for the assessment of reliability. After 2 months, 2 radiologists randomly selected 40 lesions and repeated the quantitative assessment procedure. The intraobserver ICCs of the quantitative features were calculated from the 2 measurements obtained by the same radiologist. The interobserver ICCs were calculated from the 2 measurements obtained by 2 radiologists. The ICCs $<0.50$ indicated poor reliability, ICCs between 0.50 and 0.75 indicated moderate reliability, ICCs between 0.75 and 0.90 indicated good reliability, and ICCs $>0.90$ indicated 

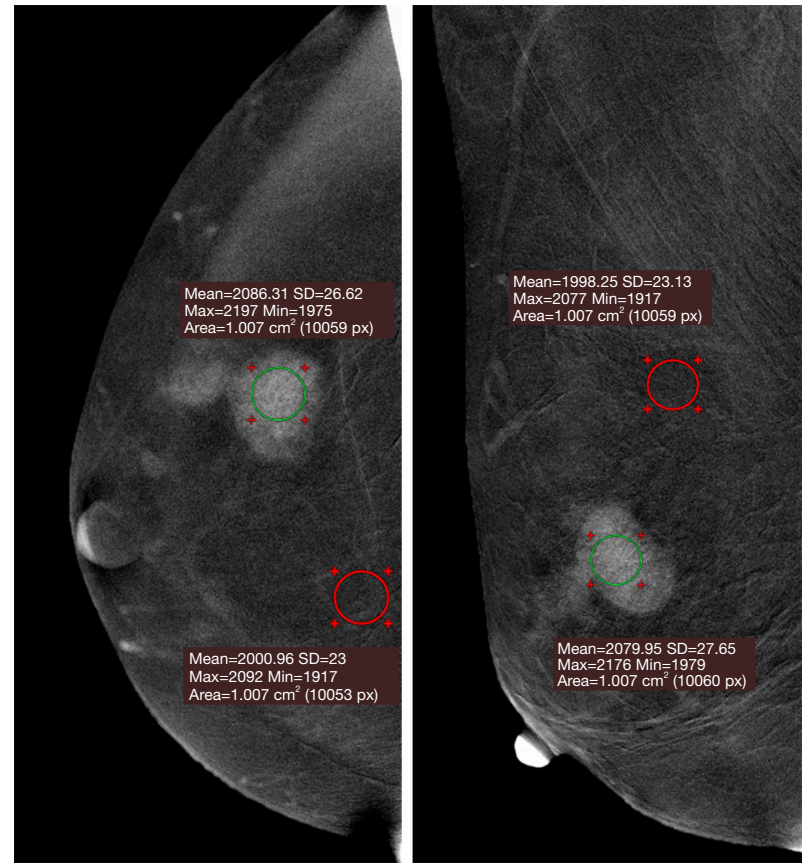

Figure 2 Quantitative assessment method on the DES images of CC (left) and MLO (right) views of the right breast. The green circle represents the lesion ROI, while the red circle represents the background ROI. The mean density and SD values of the lesion ROI and the background ROI were recorded and used to calculate the CNR and RDE features. DES, dual-energy subtraction; CC, craniocaudal; MLO, mediolateral oblique; ROI, region of interest; $\mathrm{SD}$, standard deviation; CNR, contrast-to-noise ratio; RDE, relative degree of enhancement.

excellent reliability (31).

\section{Reference standard}

The reference standard was histopathological results obtained by biopsy or surgical excision specimens within 2 weeks after CEM. All specimens were subjected to routine fixation, embedding, and sectioning, followed by hematoxylin and eosin (HE) staining and immunohistochemical (IHC) analysis. According to the World Health Organization classification of breast tumors, all specimens were reviewed by 1 breast pathologist with 15 years of experience.

The expression status of estrogen receptor (ER), progesterone receptor (PR), human epidermal growth factor receptor 2 (HER2), and $\mathrm{Ki}-67$ were recorded as the final histopathological factors. The ER or PR status was considered positive if the nuclear staining was $1 \%$ or higher. The HER2 expression was defined as positive if the IHC score was $3+$ or the fluorescence in situ hybridization amplification ratio was equal to or greater than 2.0. A Ki67 reading higher than or equal to $20 \%$ was considered a positive expression. Breast cancer is classified into 5 molecular subtypes: (I) luminal A (ER and/or PR positive, HER2 negative, Ki-67 <20\%); (II) luminal B/HER2negative (ER and/or PR positive, HER2-negative, Ki$67 \geq 20 \%$ ); (III) luminal B/HER2-positive (ER and/or PR positive, HER2-positive); (IV) HER2-enriched (ER and PR negative, HER2-positive); and (V) triple-negative breast cancer (TNBC, ER-negative, PR-negative, and HER2negative). The latter is taken as the reference standard in the case of a discrepancy between the biopsy and surgical histopathological results. In this study, the molecular subtypes were studied as dichotomous outcomes. Therefore, we reclassified the 5 molecular subtypes as luminal versus non-luminal, HER2-enriched versus. non-HER2-enriched, and TNBC versus. non-TNBC.

\section{Statistical analysis}

The statistical analyses were conducted in R 3.6.1 ( $\mathrm{R}$. Development Core Team, 2008). Continuous variables were shown as the mean values \pm SDs. Categorical variables were presented as proportions (\%). For continuous variables, Welch's $t$-tests were used to test the differences between groups. Contingency tables were used to summarize the relationship between selected outcomes and categorical variables. Phi coefficients and Cramer's V $(\varphi)$ were provided for the association between 2 binary variables and the association between 2 categorical variables, respectively. A relationship of $0.10 \leq \varphi<0.20$ indicated weak association; $0.20 \leq \varphi<0.40$ indicated moderate association; $0.40 \leq \varphi<0.60$ indicated relatively strong association; and $0.60 \leq \varphi<0.80$ indicated strong association. Multivariate logistic regression analyses of these dichotomous outcomes were further conducted for both categorical and continuous independent variables, with 2 -sided $\mathrm{P}$ values, odds ratios (ORs), and 95\% confidence intervals (CIs) provided. For logistic regression analysis, the results were additionally adjusted for age, breast thickness, and breast density to determine whether they were potential confounders. If complete separation occurred in the logistic regression, we used Bayesian logistic regression with Student's t prior with 7 degrees of freedom and a scale of 2.5 for the logit link (32). For the Bayesian approach, the $\mathrm{P}$ values, posterior median, and $95 \%$ credible 
Table 1 Clinicopathological characteristics of participants and lesions

\begin{tabular}{|c|c|c|}
\hline Characteristic & Description & Proportion (\%) \\
\hline \multirow[t]{2}{*}{ Age } & $<45$ years & $35 / 151(23.2 \%)$ \\
\hline & $\geq 45$ years & 116/151 (76.8\%) \\
\hline \multirow[t]{2}{*}{ Breast density } & $a-b$ & $48 / 151(31.8 \%)$ \\
\hline & $c-d$ & $103 / 151(68.2 \%)$ \\
\hline \multirow[t]{2}{*}{ Degree of BPE } & Minimal-mild & $113 / 151(74.8 \%)$ \\
\hline & Moderate-marked & $38 / 151(25.2 \%)$ \\
\hline \multirow[t]{2}{*}{ Lesion size } & $<20 \mathrm{~mm}$ & $49 / 160(30.6 \%)$ \\
\hline & $\geq 20 \mathrm{~mm}$ & $111 / 160(69.4 \%)$ \\
\hline \multirow[t]{2}{*}{ Breast thickness } & $<50 \mathrm{~mm}$ & $74 / 160(46.3 \%)$ \\
\hline & $\geq 50 \mathrm{~mm}$ & $86 / 160(53.7 \%)$ \\
\hline \multirow[t]{2}{*}{ Histological grade* } & Grade I-II & $77 / 126(61.1 \%)$ \\
\hline & Grade III & $49 / 126(38.9 \%)$ \\
\hline \multirow[t]{3}{*}{ Histological type } & Ductal & $147 / 160(91.9 \%)$ \\
\hline & Lobular & $4 / 160(2.5 \%)$ \\
\hline & Others & 9/160 (5.6\%) \\
\hline \multirow[t]{2}{*}{$\mathrm{ER}^{*}$} & Negative & $46 / 156(29.5 \%)$ \\
\hline & Positive & $110 / 156(70.5 \%)$ \\
\hline \multirow[t]{2}{*}{$\mathrm{PR}^{*}$} & Negative & $61 / 156(39.1 \%)$ \\
\hline & Positive & $95 / 156(60.9 \%)$ \\
\hline \multirow[t]{2}{*}{$\mathrm{HER} 2^{*}$} & Negative & $110 / 156(70.5 \%)$ \\
\hline & Positive & $46 / 156(29.5 \%)$ \\
\hline \multirow[t]{2}{*}{$\mathrm{Ki} 67^{\star}$} & Low & $41 / 156(26.3 \%)$ \\
\hline & High & 115/156 (73.7\%) \\
\hline
\end{tabular}

Data are shown as proportions with percentages in parentheses.

*, patients with missing data are not shown in this table. BPE, background parenchymal enhancement; ER, estrogen receptor; HER2, human epidermal growth factor receptor 2; PR, progesterone receptor.

interval of OR were provided. Missing data were handled by available case analysis, which used all available data to estimate parameters in the model. The significance level of all tests was set at a $\mathrm{P}$ value $<0.05$.

\section{Results}

\section{Basic participant and lesion characteristics}

The basic participant and lesion characteristics are summarized in Table 1. A total of 151 patients with 160 lesions were included in the study. The mean age of the participants was $51.2 \pm 9.1$ years (median age: 51 years; range: 21 to 70 years). Among all participants, 68.2\% (103/151) had dense breasts (c or d), and 25.2\% (38/151) had moderate to marked degrees of background parenchymal enhancement. Of all lesions, the mean lesion size was $28.5 \pm 15.2 \mathrm{~mm}, 113 / 160(70.6 \%)$ were luminal subtype, $43 / 160(26.9 \%)$ were non-luminal subtype, $21 / 160$ (13.1\%) were HER2-enriched subtype, 135/160 (84.4\%) were nonHER2-enriched subtype, 22/160 (13.8\%) were TNBC subtype, $134 / 160$ (83.8\%) were non-TNBC type, and $2.5 \%$ (4/160) were uncertain.

\section{Association between radiological findings and molecular subtypes}

The distribution of continuous radiological findings in different molecular subtype groups is shown in Table 2. The ICCs of the quantitative features are provided in the Table S2.

Compared with luminal subtype lesions, non-luminal subtype lesions showed larger lesion sizes $(\mathrm{P}=0.010)$, higher SDs of lesion density $(\mathrm{P}=0.005)$, and lower $\mathrm{CNR} /$ lesion size values $(\mathrm{P}=0.011)$. Compared with non-HER2-enriched subtype lesions, HER2 subtype lesions demonstrated higher SDs of lesion density $(\mathrm{P}=0.006)$. Although neither RDE nor CNR values revealed any significant differences among the different molecular subtype groups, TNBC subtype lesions exhibited lower $\mathrm{RDE} /$ lesion size $(\mathrm{P}=0.030)$ and $\mathrm{CNR} /$ lesion size values $(\mathrm{P}=0.041)$ than non- $\mathrm{TNBC}$ subtype lesions.

The correlations between categorical radiological findings and molecular subtypes are shown in Table 3. When the molecular subtypes were analyzed as dichotomous variables, the HER2-enriched subtype showed a significantly higher proportion of lesions with calcifications than the non-HER2-enriched subtype $(\varphi=0.178, \mathrm{P}=0.026)$. The proportion of lesions presenting with $\mathrm{AD}$ in the luminal subtype group (29/113, 25.7\%) was significantly higher than that in the non-luminal subtype group $(1 / 43,2.3 \% ; \varphi=0.265, \mathrm{P}=0.001)$. Likewise, the proportion of lesions presenting with $\mathrm{AD}$ in the TNBC group $(0 / 22,0.0 \%)$ was significantly lower than that in the non-TNBC group $(30 / 134,22.4 \% ; \varphi=0.198, \mathrm{P}=0.001)$. However, the presence of mass or asymmetry did not show a statistically significant correlation with molecular subtypes. For HER2-enriched lesions, 10/21 (47.6\%) showed nonmass enhancement, while this proportion was $33 / 134$ (24.6\%) for non-HER2-enriched lesions. The enhancement 
Table 2 Distribution of continuous radiological findings according to molecular subtypes

\begin{tabular}{|c|c|c|c|c|c|c|c|c|c|}
\hline $\begin{array}{l}\text { Continuous } \\
\text { variables }\end{array}$ & $\begin{array}{l}\text { Luminal } \\
\text { subtype } \\
(n=113)\end{array}$ & $\begin{array}{l}\text { Non-luminal } \\
\text { subtype } \\
(n=43)\end{array}$ & $\begin{array}{c}\mathrm{P} \\
\text { value }\end{array}$ & $\begin{array}{l}\text { Non-HER2 } \\
\text { subtype } \\
(n=135)\end{array}$ & $\begin{array}{l}\text { HER2 } \\
\text { subtype* } \\
(n=21)\end{array}$ & $\begin{array}{c}\mathrm{P} \\
\text { value }\end{array}$ & $\begin{array}{c}\text { Non-TNBC } \\
\text { subtype } \\
(n=134)\end{array}$ & $\begin{array}{l}\text { TNBC } \\
\text { subtype } \\
(n=22)\end{array}$ & $\begin{array}{c}\mathrm{P} \\
\text { value }\end{array}$ \\
\hline Lesion size (mm) & $26.6 \pm 14.8$ & $33.9 \pm 15.3$ & 0.010 & $27.8 \pm 15.1$ & $33.5 \pm 15.7$ & 0.136 & $27.7 \pm 15.1$ & $34.2 \pm 15.7$ & 0.081 \\
\hline $\begin{array}{l}\text { Mean lesion } \\
\text { density }\end{array}$ & $2,094.99 \pm 40.69$ & $2,096.74 \pm 43.43$ & 0.820 & $2,094.82 \pm 40.96$ & $2,099.67 \pm 44.39$ & 0.642 & $2,095.72 \pm 41.15$ & $2,093.93 \pm 43.34$ & 0.858 \\
\hline $\begin{array}{l}\text { SD of lesion } \\
\text { density }\end{array}$ & $23.28 \pm 4.36$ & $25.85 \pm 5.08$ & 0.005 & $23.56 \pm 4.58$ & $26.75 \pm 4.60$ & 0.006 & $23.83 \pm 4.56$ & $24.99 \pm 5.46$ & 0.354 \\
\hline RDE & $4.69 \pm 2.04$ & $4.85 \pm 2.26$ & 0.680 & $4.68 \pm 2.07$ & $5.06 \pm 2.29$ & 0.479 & $4.75 \pm 2.08$ & $4.65 \pm 2.27$ & 0.853 \\
\hline CNR & $4.08 \pm 1.76$ & $3.74 \pm 1.60$ & 0.244 & $4.03 \pm 1.77$ & $3.73 \pm 1.31$ & 0.364 & $4.03 \pm 1.70$ & $3.75 \pm 1.87$ & 0.509 \\
\hline
\end{tabular}

Data are presented as the mean values \pm standard deviations. *, HER2 subtype represents HER2-enriched (non-luminal) subtype. CNR, contrast-to-noise ratio; HER2, human epidermal growth factor receptor 2; SD, standard deviation; RDE, relative degree of enhancement; TNBC, triple-negative breast cancer.

type showed a weak correlation with the HER2 subtype $(\varphi=0.176, \mathrm{P}=0.029)$, while the enhancement degree did not correlate.

In addition, the distribution of continuous and categorical radiological findings according to the expression status of IHC biomarkers, including ER, PR, HER2, and Ki67 (positive vs. negative), is provided in the Tables S3-S6. The association between the radiological findings and the expression status of these biomarkers was in line with the study results.

\section{Multivariate logistic regression analysis}

Multivariate logistic regression analysis was performed based on the results in Table 2 (for continuous variables) and Table 3 (for categorical variables). In Table 4, for logistic regression analysis, larger lesion size $(\mathrm{OR}=0.97,95 \% \mathrm{CI}$ : 0.95 to $0.99, \mathrm{P}=0.013$ ) and higher $\mathrm{SD}$ of lesion density ( $\mathrm{OR}=0.88,95 \% \mathrm{CI}: 0.81$ to $0.96, \mathrm{P}=0.004)$ were associated with non-luminal subtype lesions. A higher CNR/lesion size value $(\mathrm{OR}=1.06,95 \% \mathrm{CI}: 1.01$ to $1.12, \mathrm{P}=0.012)$ and the presence of $\mathrm{AD}(\mathrm{OR}=14.50,95 \% \mathrm{CI}: 1.91$ to 110.14 , $\mathrm{P}=0.010)$ were associated with luminal subtype lesions. A higher SD of lesion density (OR $=1.16,95 \%$ CI: 1.04 to $1.28, \mathrm{P}=0.006)$, the presence of calcification $(\mathrm{OR}=2.91$, $95 \% \mathrm{CI}: 1.10$ to $7.67, \mathrm{P}=0.031$ ), and non-mass enhancement $(\mathrm{OR}=2.78,95 \% \mathrm{CI}: 1.08$ to $7.14, \mathrm{P}=0.033)$ were associated with HER2-enriched subtype lesions. A higher RDE/ lesion size $(\mathrm{OR}=0.94,95 \% \mathrm{CI}: 0.88$ to $1.00, \mathrm{P}=0.035)$, higher $\mathrm{CNR} /$ lesion size (OR $=0.94,95 \% \mathrm{CI}: 0.88$ to 1.00 , $\mathrm{P}=0.038)$, and the presence of $\mathrm{AD}(\mathrm{OR}=0.05,95 \% \mathrm{CI}: 0.00$ to $0.43, \mathrm{P}=0.022$ ) were associated with non-TNBCs. After adjustments for age, breast thickness, and breast density, except for the relationship between enhancement type and HER2 subtype, the abovementioned associations for other variables still existed (all adjusted $\mathrm{P}<0.05$ ).

Furthermore, the multivariate logistic regression results between radiological findings and the expression status of ER, PR, HER2, and Ki67 are provided in the Tables S7,S8.

\section{Discussion}

In this study, we evaluated the relationship between CEM image features and the molecular subtypes of breast cancer. The results showed that 3 quantitative enhancement features, SD of lesion density, RDE/lesion size, and CNR/ lesion size, were correlated with molecular subtypes. For qualitative image features, the presence of calcification, the presence of $\mathrm{AD}$, and enhancement type were correlated with molecular subtypes.

For the quantitative features, except that the SD of lesion density showed moderate reliability (intraobserver ICC $=0.706$; interobserver ICC $=0.678$ ), all the other quantitative features showed good to excellent intraobserver (ICC: $0.819-0.933$ ) and interobserver reliability (ICC: 0.824 $0.903)$. This is probably because the SD of lesion density is 
Table 3 Correlation between categorical radiological findings and molecular subtypes

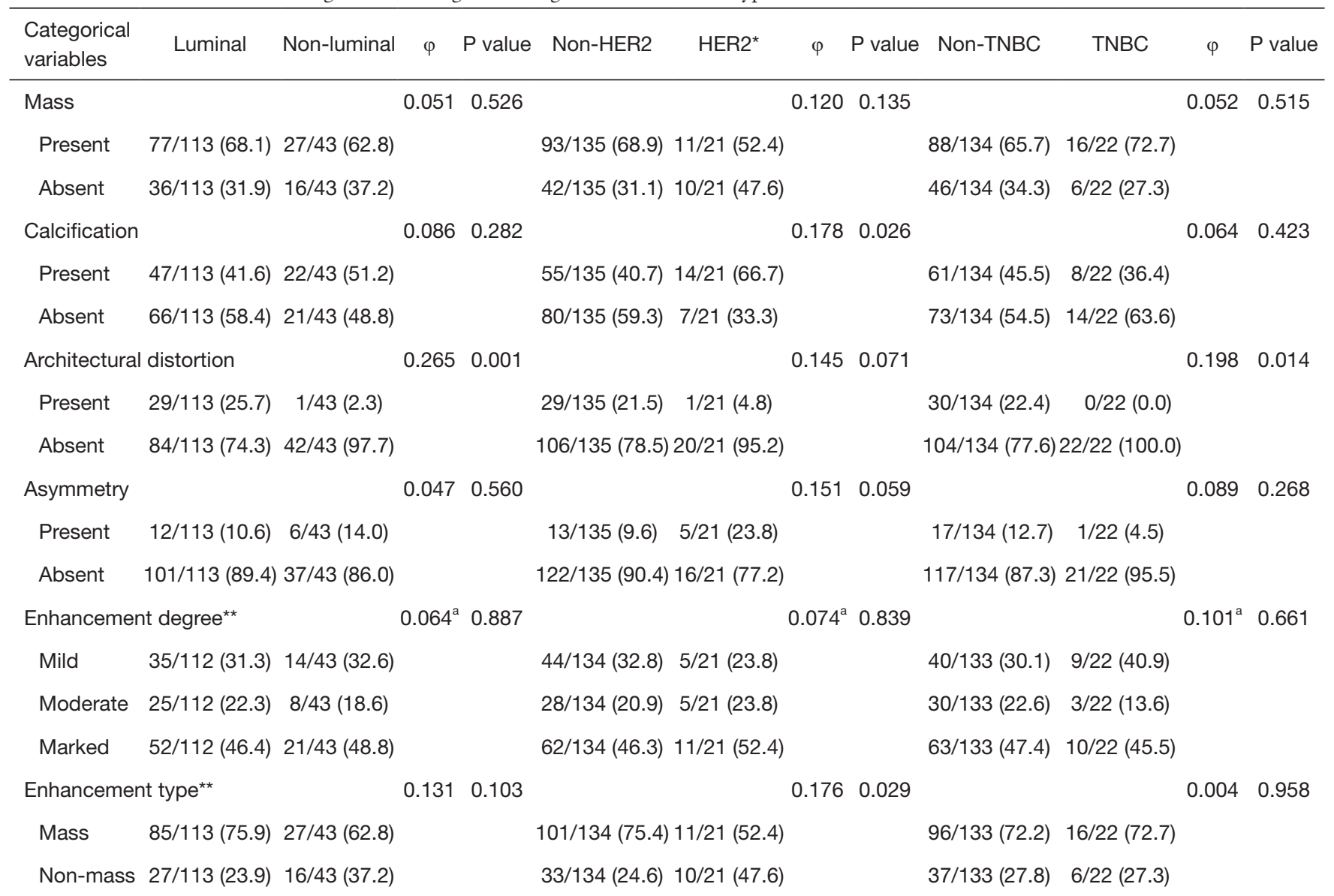

Data are shown as proportions with percentages in parentheses. ${ }^{*}$, HER2 subtype represents HER2-enriched (non-luminal) subtype. ${ }^{* *}$, Lesions with no enhancement were not included in this table. ${ }^{a}$, Cramer's $\mathrm{V}(\varphi)$ was calculated to determine associations between two categorical variables. HER2, human epidermal growth factor receptor 2; TNBC, triple-negative breast cancer.

more prone to be influenced by the manual placement of lesion ROIs. In the future, a semiautomatic or automatic quantitative method may further improve the repeatability of these image features.

It is known that breast cancer has a close association with tumor angiogenesis, which is the basis of contrast enhancement in CEM images. Several previous studies have analyzed the enhancement characteristics of different molecular subtypes of breast cancers on breast MRI. Studies using CEM images to carry out quantitative assessments of contrast enhancement have been mainly focused on differentiating benign and malignant breast lesions. Only one study found that the enhancement intensity in CEM images of ER- or PR-positive lesions were weaker than that in CEM images of negative lesions, while HER-2positive lesions showed stronger enhancement than HER2- negative lesions (33). However, in this study, mean lesion density, RDE, CNR, and subjective enhancement degree were unrelated to molecular subtypes. Our results may indicate that in CEM images, the peak enhancement degree of the lesions alone may not provide sufficient information in differentiating between different molecular subtypes of breast cancers. However, when we considered lesion size, 2 quantitative features, RDE/lesion size, and CNR/lesion size, showed associations with molecular subtypes. Some studies $(30,34)$ have pointed out that the enhancement intensity in CEM images depends on the size of the tumor and is more obvious in larger lesions than in smaller lesions.

For this reason, the authors defined these 2 image features in an attempt to eliminate the influence of tissue overlapping and speculated that after dividing by lesion sizes, these quantitative indices might be more 
Table 4 Multivariate logistic regression analysis between radiological findings and molecular subtypes

\begin{tabular}{|c|c|c|c|c|c|c|}
\hline \multirow{2}{*}{ Independent variables } & \multicolumn{6}{|c|}{ Dependent variables } \\
\hline & OR $(95 \% \mathrm{Cl})$ & $P$ value & OR $(95 \% \mathrm{Cl})$ & $P$ value & OR $(95 \% \mathrm{Cl})^{\star *}$ & $P$ value \\
\hline \multirow[t]{2}{*}{ Lesion size (mm) } & $0.97(0.95-0.99)$ & 0.013 & 1.02 (0.99-1.05) & 0.125 & $1.02(1.00-1.05)$ & 0.074 \\
\hline & $0.97(0.95-1.00)^{\star \star}$ & $0.036^{\star \star}$ & $1.02(0.99-1.04)^{\star \star}$ & $0.262^{\star \star}$ & $1.02(1.00-1.05)^{\star *}$ & $0.100^{* *}$ \\
\hline SD of lesion density & $0.90(0.82-0.98)^{\star \star}$ & $0.015^{\star \star}$ & $1.14(1.02-1.28)^{\star \star}$ & $0.020^{\star \star}$ & $1.03(0.94-1.14)^{\star \star}$ & $0.517^{\star *}$ \\
\hline \multirow[t]{2}{*}{ RDE/lesion size } & $1.04(0.99-1.08)$ & 0.110 & $1.00(0.95-1.04)$ & 0.904 & $0.94(0.88-1.00)$ & 0.035 \\
\hline & $1.03(0.99-1.07)^{\star \star}$ & $0.114^{\star \star}$ & $0.99(0.95-1.04)^{\star *}$ & $0.817^{\star \star}$ & $0.94(0.88-1.00)^{\star *}$ & $0.037^{\star *}$ \\
\hline CNR/lesion size & $1.06(1.01-1.12)$ & 0.012 & $0.96(0.90-1.02)$ & 0.192 & $0.94(0.88-1.00)$ & 0.038 \\
\hline Presence of calcification & $0.64(0.31-1.34)^{\star \star}$ & $0.237^{\star *}$ & $3.08(1.13-8.38)^{\star \star}$ & $0.028^{\star \star}$ & $0.72(0.27-1.90)^{\star \star}$ & $0.510^{\star *}$ \\
\hline \multirow[t]{2}{*}{ Presence of architectural distortion } & $14.50(1.91-110.14)$ & 0.010 & $0.18(0.02-1.42)$ & 0.104 & $0.05(0.00-0.43)^{a}$ & 0.022 \\
\hline & $16.99(2.19-132.12)^{\star *}$ & $0.007^{\star \star}$ & $0.17(0.02-1.34)^{\star *}$ & $0.092^{\star *}$ & $0.04(0.00-0.39)^{\mathrm{a}, * *}$ & $0.015^{\star *}$ \\
\hline \multirow[t]{2}{*}{ Enhancement type } & $0.54(0.25-1.14)$ & 0.105 & $2.78(1.08-7.14)$ & 0.033 & $0.97(0.35-2.68)$ & 0.958 \\
\hline & $0.59(0.27-1.29)^{\star \star}$ & $0.186^{\star *}$ & $2.43(0.93-6.35)^{\star \star}$ & $0.071^{\star \star}$ & $0.89(0.30-2.60)^{\star \star}$ & $0.831^{* *}$ \\
\hline
\end{tabular}

*, HER2 subtype represents HER2-enriched (non-luminal) subtype. ${ }^{*}$, the ORs and P values were adjusted for age, breast thickness and breast density. ${ }^{a}$, Bayesian logistic regression was used due to complete separation. The posterior median and $95 \%$ credible interval of $\mathrm{OR}$ are provided. OR, odds ratio; $\mathrm{Cl}$, confidence interval; SD, standard deviation; CNR, contrast-to-noise ratio; HER2, human epidermal growth factor receptor 2; RDE, relative degree of enhancement; TNBC, triple-negative breast cancer.

representative to reflect the intrinsic lesion characteristics. Both quantitative features (RDE/lesion size and CNR/ lesion size) showed lower levels in biologically more aggressive cancers. There are several possible reasons for this observation. First, compared with luminal subtype breast cancers, HER2-enriched or TNBCs generally have a higher histological grade and larger lesion size (35), thus reducing the quantitative signal intensity per unit length. Second, these lesions are more prone to be necrotic (35), which may lower the overall signal intensity of enhancement during breast compression, especially in this 2-dimensional CEM technique. Third, these lesions may demonstrate a more rapid washout pattern of enhancement. The highest peak enhancement value may not be captured during the CEM procedure. Fourth, the SD of lesion density may reflect the heterogeneity of the lesions to some extent and may be expected to be greater in more aggressive cancers. In our study, the SD of lesion density was higher in the non-luminal and HER2-enriched groups, which lowered the CNR value (Table 2). Although it is not sufficient to directly predict the clinical progress, aggressiveness, or prognosis of the lesions using these quantitative features, the results of this study will be helpful in understanding and diagnosing different molecular subtypes of breast cancers using the CEM technique.

Several studies have found that ER-positive tumors are prone to be irregularly shaped with spiculated margins, while ER-negative tumors tend to be associated with round shapes with smooth and circumscribed margins (36-39). Although our study did not analyze the shape and margins of the tumors, we investigated the presence of $\mathrm{AD}$ between different molecular subtypes. Our results showed that $\mathrm{AD}$ occurred more often in luminal subtype breast cancers and less often in TNBCs. Since the spiculated margins of masses or spicules of AD may represent similar pathological processes, including tumor infiltration, a desmoplastic response in the adjacent stroma, or periductal fibrosis at the cellular level (40), we considered our results to be in line with previous studies (36-39).

Studies have found that HER2 overexpression is 
associated with the presence of calcifications and that no associated calcifications are signatures of TNBC $(41,42)$. Tan et al. found that women with microcalcification clusters in the affected breast are less likely to have TNBCs than those with luminal A breast cancers (43). Our study also showed that the presence of calcifications is associated with the HER2-enriched subtype. The underlying biological mechanism is probably that HER2-enriched tumors are more aggressive and more likely to undergo fast proliferation and necrosis, leading to microcalcifications in mammary ducts $(41,44)$. In our study, although the proportion of lesions with calcifications in the TNBC group was lower than that in the non-TNBC group, the difference was not statistically significant (Table 3). This is probably because the proportion of calcifications in non-TNBCs was slightly lower than before due to the inadequate time of calcification formation as the rate of early diagnosis of breast cancers increases.

Our study has several limitations. First, the sample size of this study is small, and the retrospective nature of this study may potentially have caused a biased result. Larger sample size is warranted. Second, we did not correlate the imaging features with distant metastasis, local recurrence, or patient survival. These factors may reflect the invasiveness of breast cancers more directly. Third, we did not perform a dynamic enhancement analysis of the lesions. Instead, we only considered the most obvious enhancement results. Several studies have found a correlation between kinetic enhancement features from dynamic contrast-enhanced (DCE)-MRI and molecular subtypes of breast cancers $(6,7)$. Although we could not investigate the kinetic curve pattern using CEM images, it would be interesting to analyze the enhancement patterns of lesions of different molecular subtypes between the early and late phases.

In conclusion, this study provides statistical evidence of associations between the quantitative and qualitative image features of CEM and molecular subtypes of breast cancers.

\section{Acknowledgments}

The authors are thankful to Boran Pang, MD, for providing technical support and inspiration in experimental design. Permission was provided by him.

Funding: This project was supported by the grant from the Clinical Research Plan of SHDC (SHDC2020CR2008A), the National Natural Science Foundation of China (NSFC 82071878), Shanghai Science and Technology Foundation (19DZ1930502), Shanghai Anticancer Association EYAS
PROJECT (SACA-CY20B01), Shanghai Anticancer Association FLIGHT PROJECT (SACA-AX-201903), and Shanghai Science and Technology Committee Foundation (21Y1191020).

\section{Footnote}

Reporting Checklist: The authors have completed the MDAR checklist. Available at https://dx.doi.org/10.21037/ qims-21-589

Conflicts of Interest: All authors have completed the ICMJE uniform disclosure form (available at https://dx.doi. org/10.21037/qims-21-589). The authors have no conflicts of interest to declare.

Ethical Statement: The authors are accountable for all aspects of the work in ensuring that questions related to the accuracy or integrity of any part of the work are appropriately investigated and resolved. The study was conducted in accordance with the Declaration of Helsinki (as revised in 2013). The study was approved by the Ethics Committee of each center (2006219-14; [2019]298) and individual consent for this retrospective analysis was waived.

Open Access Statement: This is an Open Access article distributed in accordance with the Creative Commons Attribution-NonCommercial-NoDerivs 4.0 International License (CC BY-NC-ND 4.0), which permits the noncommercial replication and distribution of the article with the strict proviso that no changes or edits are made and the original work is properly cited (including links to both the formal publication through the relevant DOI and the license). See: https://creativecommons.org/licenses/by-nc-nd/4.0/.

\section{References}

1. Bray F, Ferlay J, Soerjomataram I, Siegel RL, Torre LA, Jemal A. Global cancer statistics 2018: GLOBOCAN estimates of incidence and mortality worldwide for 36 cancers in 185 countries. CA Cancer J Clin 2018;68:394-424.

2. Bedard PL, Hansen AR, Ratain MJ, Siu LL. Tumour heterogeneity in the clinic. Nature 2013;501:355-64.

3. Li H, Zhu Y, Burnside ES, Huang E, Drukker K, Hoadley KA, Fan C, Conzen SD, Zuley M, Net JM, Sutton E, Whitman GJ, Morris E, Perou CM, Ji Y, Giger ML. Quantitative MRI radiomics in the prediction of molecular classifications of breast cancer subtypes in the TCGA/ 
TCIA data set. NPJ Breast Cancer 2016. doi: 10.1038/ npjbcancer.2016.12.

4. Lewin JM, Isaacs PK, Vance V, Larke FJ. Dual-energy contrast-enhanced digital subtraction mammography: feasibility. Radiology 2003;229:261-8.

5. Diekmann F, Bick U. Tomosynthesis and contrastenhanced digital mammography: recent advances in digital mammography. Eur Radiol 2007;17:3086-92.

6. Blaschke E, Abe H. MRI phenotype of breast cancer: Kinetic assessment for molecular subtypes. J Magn Reson Imaging 2015;42:920-4.

7. Yamaguchi K, Abe H, Newstead GM, Egashira R, Nakazono T, Imaizumi T, Irie H. Intratumoral heterogeneity of the distribution of kinetic parameters in breast cancer: comparison based on the molecular subtypes of invasive breast cancer. Breast Cancer 2015;22:496-502.

8. Alili C, Pages E, Curros Doyon F, Perrochia H, Millet I, Taourel P. Correlation between MR imaging - prognosis factors and molecular classification of breast cancers. Diagn Interv Imaging 2014;95:235-42.

9. Kim JY, Kim SH, Kim YJ, Kang BJ, An YY, Lee AW, Song BJ, Park YS, Lee HB. Enhancement parameters on dynamic contrast enhanced breast MRI: do they correlate with prognostic factors and subtypes of breast cancers? Magn Reson Imaging 2015;33:72-80.

10. Lalji UC, Jeukens CR, Houben I, Nelemans PJ, van Engen RE, van Wylick E, Beets-Tan RG, Wildberger JE, Paulis LE, Lobbes MB. Evaluation of low-energy contrastenhanced spectral mammography images by comparing them to full-field digital mammography using EUREF image quality criteria. Eur Radiol 2015;25:2813-20.

11. Francescone MA, Jochelson MS, Dershaw DD, Sung JS, Hughes MC, Zheng J, Moskowitz C, Morris EA. Low energy mammogram obtained in contrast-enhanced digital mammography (CEDM) is comparable to routine full-field digital mammography (FFDM). Eur J Radiol 2014;83:1350-5.

12. Patel BK, Lobbes MBI, Lewin J. Contrast Enhanced Spectral Mammography: A Review. Semin Ultrasound CT MR 2018;39:70-9.

13. Bhimani C, Matta D, Roth RG, Liao L, Tinney E, Brill K, Germaine P. Contrast-enhanced Spectral Mammography: Technique, Indications, and Clinical Applications. Acad Radiol 2017;24:84-8.

14. Rudnicki W, Heinze S, Niemiec J, Kojs Z, Sas-Korczynska B, Hendrick E, Luczynska E. Correlation between quantitative assessment of contrast enhancement in contrast-enhanced spectral mammography (CESM) and histopathology-preliminary results. Eur Radiol 2019;29:6220-6.

15. Rudnicki W, Heinze S, Popiela T, Kojs Z, Luczynska E. Quantitative Assessment of Contrast Enhancement on Contrast Enhancement Spectral Mammography (CESM) and Comparison With Qualitative Assessment. Anticancer Res 2020;40:2925-32.

16. Lv Y, Chi X, Sun B, Lin S, Xing D. Diagnostic Value of Quantitative Gray-Scale Analysis of Contrast-Enhanced Spectral Mammography for Benign and Malignant Breast Lesions. J Comput Assist Tomogr 2020;44:405-12.

17. Tsigginou A, Gkali C, Chalazonitis A, Feida E, Vlachos DE, Zagouri F, Rellias I, Dimitrakakis C. Adding the power of iodinated contrast media to the credibility of mammography in breast cancer diagnosis. Br J Radiol 2016;89:20160397.

18. Deng CY, Juan YH, Cheung YC, Lin YC, Lo YF, Lin G, Chen SC, Ng SH. Quantitative analysis of enhanced malignant and benign lesions on contrast-enhanced spectral mammography. Br J Radiol 2018;91:20170605.

19. Kamal RM, Helal MH, Mansour SM, Haggag MA, Nada OM, Farahat IG, Alieldin NH. Can we apply the MRI BI-RADS lexicon morphology descriptors on contrast-enhanced spectral mammography? Br J Radiol 2016;89:20160157.

20. Mohamed Kamal R, Hussien Helal M, Wessam R, Mahmoud Mansour S, Godda I, Alieldin N. Contrastenhanced spectral mammography: Impact of the qualitative morphology descriptors on the diagnosis of breast lesions. Eur J Radiol 2015;84:1049-55.

21. Xu W, Zheng B, Chen W, Wen C, Zeng H, He Z, Qin G, Li Y. Can the delayed phase of quantitative contrastenhanced mammography improve the diagnostic performance on breast masses? Quant Imaging Med Surg 2021;11:3684-97.

22. Marino MA, Pinker K, Leithner D, Sung J, Avendano D, Morris EA, Jochelson M. Contrast-Enhanced Mammography and Radiomics Analysis for Noninvasive Breast Cancer Characterization: Initial Results. Mol Imaging Biol 2020;22:780-7.

23. Marino MA, Leithner D, Sung J, Avendano D, Morris EA, Pinker K, Jochelson MS. Radiomics for Tumor Characterization in Breast Cancer Patients: A Feasibility Study Comparing Contrast-Enhanced Mammography and Magnetic Resonance Imaging. Diagnostics (Basel) 2020;10:492.

24. Mao N, Yin P, Li Q, Wang Q, Liu M, Ma H, Dong J, Che K, Wang Z, Duan S, Zhang X, Hong N, Xie H. 
Radiomics nomogram of contrast-enhanced spectral mammography for prediction of axillary lymph node metastasis in breast cancer: a multicenter study. Eur Radiol 2020;30:6732-9.

25. La Forgia D, Fanizzi A, Campobasso F, Bellotti R, Didonna V, Lorusso V, Moschetta M, Massafra R, Tamborra P, Tangaro S, Telegrafo M, Pastena MI, Zito A. Radiomic Analysis in Contrast-Enhanced Spectral Mammography for Predicting Breast Cancer Histological Outcome. Diagnostics (Basel) 2020;10:708.

26. Ghaderi KF, Phillips J, Perry H, Lotfi P, Mehta TS. Contrast-enhanced Mammography: Current Applications and Future Directions. Radiographics 2019;39:1907-20.

27. D’Orsi CJ, Sickles EA, Mendelson EB, Morris EA. ACR BI-RADS® Atlas. Breast Imaging Reporting and Data System. Reston, VA: American College of Radiology, 2013.

28. Baldelli P, Phelan N, Egan G. A novel method for contrast-to-noise ratio (CNR) evaluation of digital mammography detectors. Eur Radiol 2009;19:2275-85.

29. Heck L, Dierolf M, Jud C, Eggl E, Sellerer T, Mechlem K, Günther B, Achterhold K, Gleich B, Metz S, Pfeiffer D, Kröninger K, Herzen J. Contrast-enhanced spectral mammography with a compact synchrotron source. PLoS One 2019;14:e0222816.

30. Dromain C, Vietti-Violi N, Meuwly JY. Angiomammography: A review of current evidences. Diagn Interv Imaging 2019;100:593-605.

31. Koo TK, Li MY. A Guideline of Selecting and Reporting Intraclass Correlation Coefficients for Reliability Research. J Chiropr Med 2016;15:155-63.

32. Ghosh J, Li Y, Mitra R. On the Use of Cauchy Prior Distributions for Bayesian Logistic Regression. Bayesian Anal 2015;13:359-83.

33. Liu Y, Zhao S, Huang J, Zhang X, Qin Y, Zhong H, Yu J. Quantitative Analysis of Enhancement Intensity and Patterns on Contrast-enhanced Spectral Mammography. Sci Rep 2020;10:9807.

34. Luczynska E, Niemiec J, Heinze S, Adamczyk A, Ambicka A, Marcyniuk P, Rudnicki W, Mitus JW, Dyczek S, Rys J, Sas-Korczynska B. Intensity and Pattern of Enhancement on CESM: Prognostic Significance and its Relation to Expression of Podoplanin in Tumor Stroma - A Preliminary Report. Anticancer Res 2018;38:1085-95.

35. Youk JH, Son EJ, Chung J, Kim JA, Kim EK. Triple-negative invasive breast cancer on dynamic contrast-enhanced and diffusion-weighted MR imaging: comparison with other breast cancer subtypes. Eur Radiol 2012;22:1724-34.

36. Mazurowski MA, Zhang J, Grimm LJ, Yoon SC, Silber
JI. Radiogenomic analysis of breast cancer: luminal $\mathrm{B}$ molecular subtype is associated with enhancement dynamics at MR imaging. Radiology 2014;273:365-72.

37. Grimm LJ, Zhang J, Mazurowski MA. Computational approach to radiogenomics of breast cancer: Luminal A and luminal B molecular subtypes are associated with imaging features on routine breast MRI extracted using computer vision algorithms. J Magn Reson Imaging 2015;42:902-7.

38. Grimm LJ, Zhang J, Baker JA, Soo MS, Johnson KS, Mazurowski MA. Relationships Between MRI Breast Imaging-Reporting and Data System (BI-RADS) Lexicon Descriptors and Breast Cancer Molecular Subtypes: Internal Enhancement is Associated with Luminal B Subtype. Breast J 2017;23:579-82.

39. Wang Y, Ikeda DM, Narasimhan B, Longacre TA, Bleicher RJ, Pal S, Jackman RJ, Jeffrey SS. Estrogen receptor-negative invasive breast cancer: imaging features of tumors with and without human epidermal growth factor receptor type 2 overexpression. Radiology 2008;246:367-75.

40. Franquet T, De Miguel C, Cozcolluela R, Donoso L. Spiculated lesions of the breast: mammographic-pathologic correlation. Radiographics 1993;13:841-52.

41. Elias SG, Adams A, Wisner DJ, Esserman LJ, van't Veer LJ, Mali WP, Gilhuijs KG, Hylton NM. Imaging features of HER2 overexpression in breast cancer: a systematic review and meta-analysis. Cancer Epidemiol Biomarkers Prev 2014;23:1464-83.

42. Lamb PM, Perry NM, Vinnicombe SJ, Wells CA. Correlation between ultrasound characteristics, mammographic findings and histological grade in patients with invasive ductal carcinoma of the breast. Clin Radiol 2000;55:40-4.

43. Tan PS, Ali MA, Eriksson M, Hall P, Humphreys K, Czene K. Mammography features for early markers of aggressive breast cancer subtypes and tumor characteristics: A population-based cohort study. Int J Cancer 2021;148:1351-9.

44. Tse GM, Tan PH, Pang AL, Tang AP, Cheung HS. Calcification in breast lesions: pathologists' perspective. J Clin Pathol 2008;61:145-51.

Cite this article as: Wang S, Wang Z, Li R, You C, Mao N, Jiang T, Wang Z, Xie H, Gu Y. Association between quantitative and qualitative image features of contrast-enhanced mammography and molecular subtypes of breast cancer. Quant Imaging Med Surg 2022;12(2):1270-1280. doi: 10.21037/qims21-589 
Supplementary

Table S1 The qualitative and quantitative features of CEM images

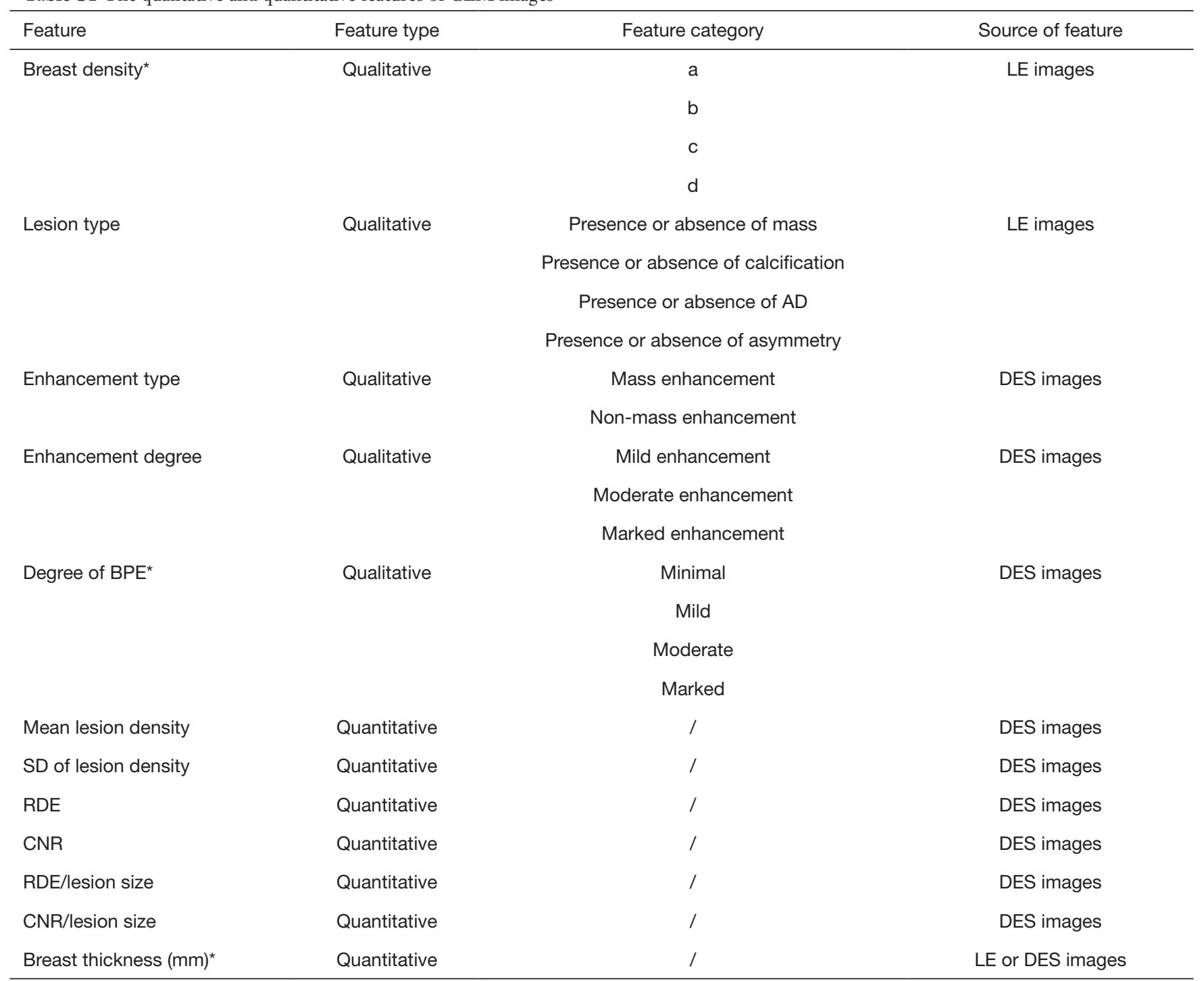

* The three features were not included in the statistical analysis. AD, architectural distortion; BPE, background parenchymal enhancement; CEM, contrast-enhanced mammography; CNR, contrast-to-noise ratio; DES, dual-energy subtraction; LE, low energy; RDE, relative degree of enhancement; SD, standard deviation. 
Table S2 The ICCs of the quantitative features of CEM images

\begin{tabular}{lcc}
\hline Quantitative features & Intraobserver ICC & Interobserver ICC* \\
\hline Mean lesion density & 0.933 & 0.902 \\
SD of lesion density & 0.706 & 0.678 \\
RDE & 0.917 & 0.903 \\
CNR & 0.819 & 0.824 \\
RDE/lesion size & 0.888 & 0.830 \\
CNR/lesion size & 0.876 & 0.851 \\
\hline
\end{tabular}

* The intraobserver ICCs of the quantitative features were calculated by the two measurements obtained by the same radiologist. The interobserver ICCs of the quantitative features were calculated by the two measurements obtained by two radiologists. CEM, contrastenhanced mammography; CNR, contrast-to-noise ratio; ICC, intraclass correlation coefficients; RDE, relative degree of enhancement; SD, standard deviation.

Table S3 The distribution of continuous radiological findings according to expression status of ER, and PR

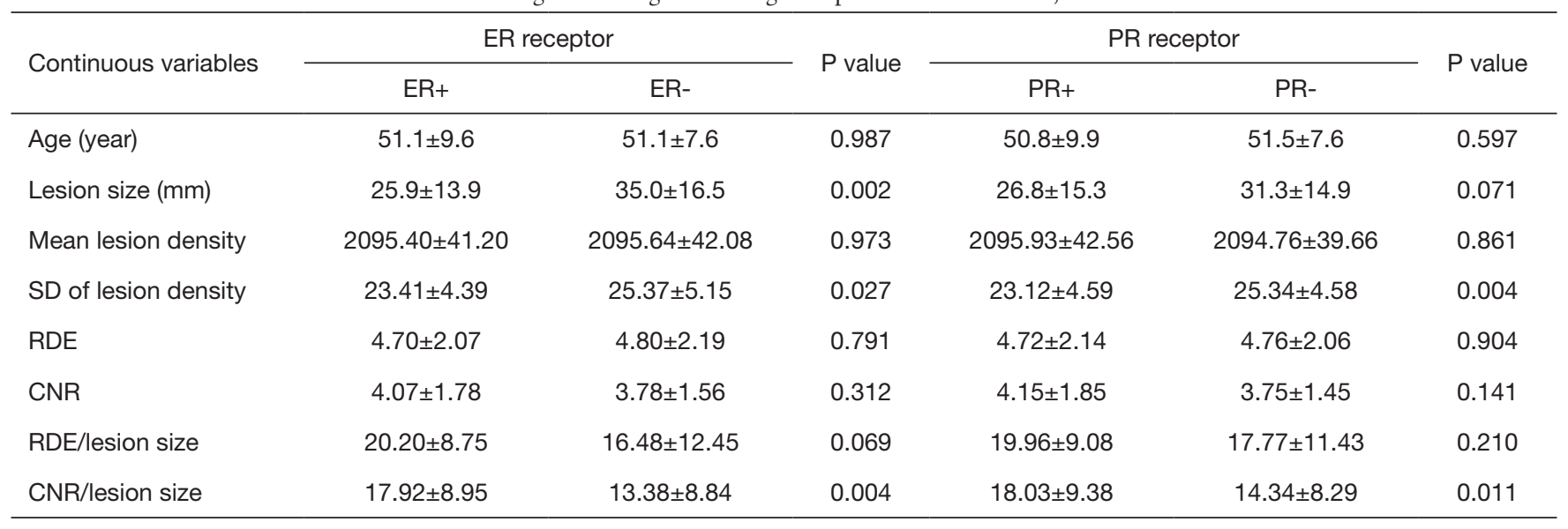

Data are presented as the mean values \pm standard deviations. CNR, contrast-to-noise ratio; ER, estrogen receptor; PR, progestogen receptor; $\mathrm{RDE}$, relative degree of enhancement; $\mathrm{SD}$, standard deviation.

Table S4 The distribution of continuous radiological findings according to expression status of HER2, and Ki-67

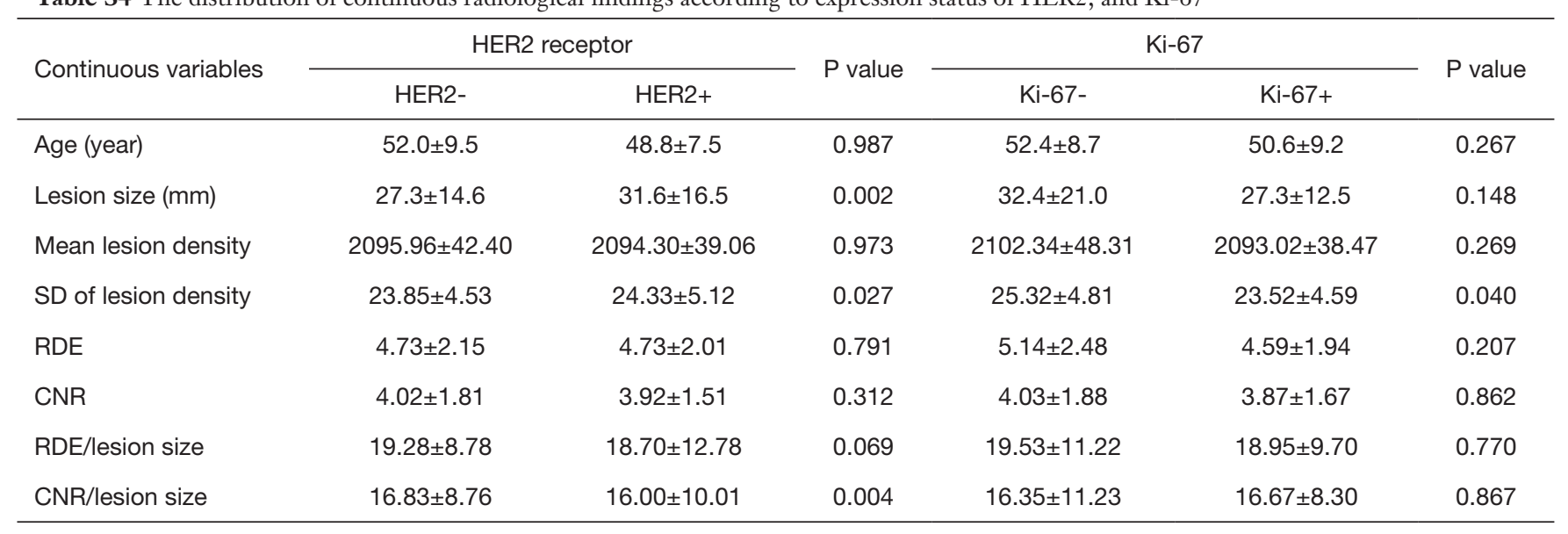

Data are presented as the mean values \pm standard deviations. CNR, contrast-to-noise ratio; HER2, human epidermal growth factor receptor 2; RDE, relative degree of enhancement; SD, standard deviation. 
Table S5 The correlation between categorical radiological findings and expression status of ER, and PR

\begin{tabular}{|c|c|c|c|c|c|c|c|c|}
\hline Categorical variables & $\mathrm{ER}+$ & ER- & $\varphi$ & $P$ value & PR+ & PR- & $\varphi$ & $P$ value \\
\hline Present & $77 / 110(70.0)$ & $27 / 46(58.7)$ & & & $64 / 95(67.4)$ & $40 / 61(65.6)$ & & \\
\hline Absent & $33 / 110$ (30.0) & 19/46 (41.3) & & & 31/95 (32.6) & 21/61 (34.4) & & \\
\hline Calcification & & & 0.075 & 0.348 & & & 0.159 & 0.046 \\
\hline Absent & 64/110 (58.2) & 23/46 (50.0) & & & $59 / 95(62.1)$ & 28/61 (45.9) & & \\
\hline Architectural distortion & & & 0.280 & $<0.001$ & & & 0.324 & $<0.001$ \\
\hline Present & $29 / 110(26.4)$ & $1 / 46(2.2)$ & & & 28/95 (29.5) & 2/61 (3.3) & & \\
\hline Absent & $81 / 110(73.6)$ & 45/46 (97.8) & & & 67/95 (70.5) & $59 / 61(96.7)$ & & \\
\hline Absent & $100 / 110(90.9)$ & $38 / 46(82.6)$ & & & 86/95 (90.5) & $52 / 61(85.2)$ & & \\
\hline Enhancement degree ${ }^{*}$ & & & $0.059^{a}$ & 0.910 & & & $0.118^{\mathrm{a}}$ & 0.536 \\
\hline Mild & $34 / 109$ (31.2) & 15/46 (32.6) & & & 33/94 (35.1) & 16/61 (26.2) & & \\
\hline Moderate & 24/109 (22.0) & 9/46 (19.6) & & & 18/94 (19.1) & $15 / 61(24.6)$ & & \\
\hline Marked & $51 / 109(46.8)$ & 22/46 (47.8) & & & 43/94 (45.7) & $30 / 61$ (49.2) & & \\
\hline Enhancement type ${ }^{*}$ & & & 0.197 & 0.014 & & & 0.032 & 0.692 \\
\hline Mass & $85 / 109(78.0)$ & $19 / 46(41.3)$ & & & 69/94 (73.4) & $43 / 61(70.5)$ & & \\
\hline Non-mass & 24/109 (22.0) & $27 / 46(58.7)$ & & & 25/94 (26.6) & 18/61 (29.5) & & \\
\hline
\end{tabular}

Data are shown as proportions with percentages in parentheses; * Lesions with no enhancement are not shown in this table; ${ }^{a}$ Cramer's $V(\varphi)$ was provided for association between two categorical variables; ER, estrogen receptor; PR, progestogen receptor. 
Table S6 The correlation between categorical radiological findings and expression status of HER2, and Ki-67

\begin{tabular}{|c|c|c|c|c|c|c|c|c|}
\hline Categorical variables & HER2- & HER2+ & $\varphi$ & $P$ value & Ki-67- & $\mathrm{Ki}-67+$ & $\varphi$ & $P$ value \\
\hline Present & $82 / 110(74.5)$ & $22 / 46(47.8)$ & & & $26 / 41(63.4)$ & $78 / 115$ (67.8) & & \\
\hline Absent & $28 / 110(25.5)$ & $24 / 46(52.2)$ & & & $15 / 41(36.6)$ & $37 / 115$ (32.2) & & \\
\hline Calcification & & & 0.217 & 0.007 & & & 0.239 & 0.003 \\
\hline Absent & $69 / 110(62.7)$ & $18 / 46(39.1)$ & & & $31 / 41(75.6)$ & $56 / 115(48.7)$ & & \\
\hline Architectural distortion & & & 0.209 & 0.009 & & & 0.115 & 0.150 \\
\hline Present & $27 / 110(24.5)$ & $3 / 46(6.5)$ & & & $11 / 41(26.8)$ & $19 / 115(16.5)$ & & \\
\hline Absent & $83 / 110(75.5)$ & $43 / 46(93.5)$ & & & $30 / 41(73.2)$ & $96 / 115$ (83.5) & & \\
\hline Absent & $102 / 110(92.7)$ & $36 / 46(78.3)$ & & & $38 / 41(92.7)$ & $100 / 115(87.0)$ & & \\
\hline Enhancement degree & & & $0.055^{\mathrm{a}}$ & 0.924 & & & $0.149^{a}$ & 0.323 \\
\hline Mild & $34 / 109$ (31.2) & $15 / 46(32.6)$ & & & $11 / 40(27.5)$ & $38 / 115$ (33.0) & & \\
\hline Moderate & 23/109 (21.1) & $10 / 46(21.7)$ & & & $8 / 40(20.0)$ & 25/115 (30.4) & & \\
\hline Marked & $52 / 109(47.7)$ & $21 / 46(45.7)$ & & & $21 / 40(52.5)$ & $52 / 115(45.2)$ & & \\
\hline Enhancement type* & & & 0.165 & 0.040 & & & 0.194 & 0.016 \\
\hline Mass & $84 / 109(77.1)$ & $28 / 46(60.9)$ & & & $23 / 40(57.5)$ & $89 / 115(77.4)$ & & \\
\hline Non-mass & 25/109 (22.9) & 18/46 (39.1) & & & $17 / 40(42.7)$ & 26/115 (22.6) & & \\
\hline
\end{tabular}

Data are shown as proportions with percentages in parentheses; * Lesions with no enhancement are not shown in this table; ${ }^{a} \mathrm{Cramer}$ 's $\mathrm{V}(\varphi)$ was provided for association between two categorical variables; HER2, human epidermal growth factor receptor 2. 
Table S7 Multivariate logistic regression analysis between radiological findings and expression status of ER, and PR

\begin{tabular}{|c|c|c|c|c|c|c|c|c|}
\hline \multirow{2}{*}{ Independent variables } & \multicolumn{8}{|c|}{ Dependent variables } \\
\hline & OR (95\% Cl) & $P$ value & $\mathrm{OR}_{\mathrm{ad}}(95 \% \mathrm{Cl})^{*}$ & $P$ value* & OR (95\% Cl) & $P$ value & $\mathrm{OR}_{\mathrm{ad}}(95 \% \mathrm{Cl})^{\star}$ & $P$ value* \\
\hline Lesion size (mm) & $0.96(0.94-0.99)$ & 0.002 & $0.96(0.94-0.99)$ & 0.005 & $0.98(0.96-1.00)$ & 0.079 & $0.98(0.96-1.01)$ & 0.142 \\
\hline SD of lesion density & $0.91(0.84-0.99)$ & 0.021 & $0.93(0.86-1.01)$ & 0.084 & $0.90(0.83-0.97)$ & 0.006 & $0.90(0.83-0.98)$ & 0.015 \\
\hline CNR/lesion size & 1.07 (1.02-1.12) & 0.006 & 1.07 (1.01-1.12) & 0.011 & $1.05(1.01-1.10)$ & 0.016 & 1.05 (1.01-1.09) & 0.026 \\
\hline Presence of calcification & $0.72(0.36-1.43)$ & 0.349 & $0.70(0.34-1.44)$ & 0.337 & $0.52(0.27-0.99)$ & 0.048 & $0.51(0.26-0.99)$ & 0.047 \\
\hline $\begin{array}{l}\text { Presence of architectural } 1 \\
\text { distortion }\end{array}$ & $16.11(2.12-122.24)$ & 0.007 & $19.98(2.56-156.30)$ & 0.004 & $12.33(2.82-53.97)$ & 0.001 & 14.69 (3.25-66.38) & 0.000 \\
\hline
\end{tabular}

Table S8 Multivariate logistic regression analysis between radiological findings and expression status of HER2, and Ki-67

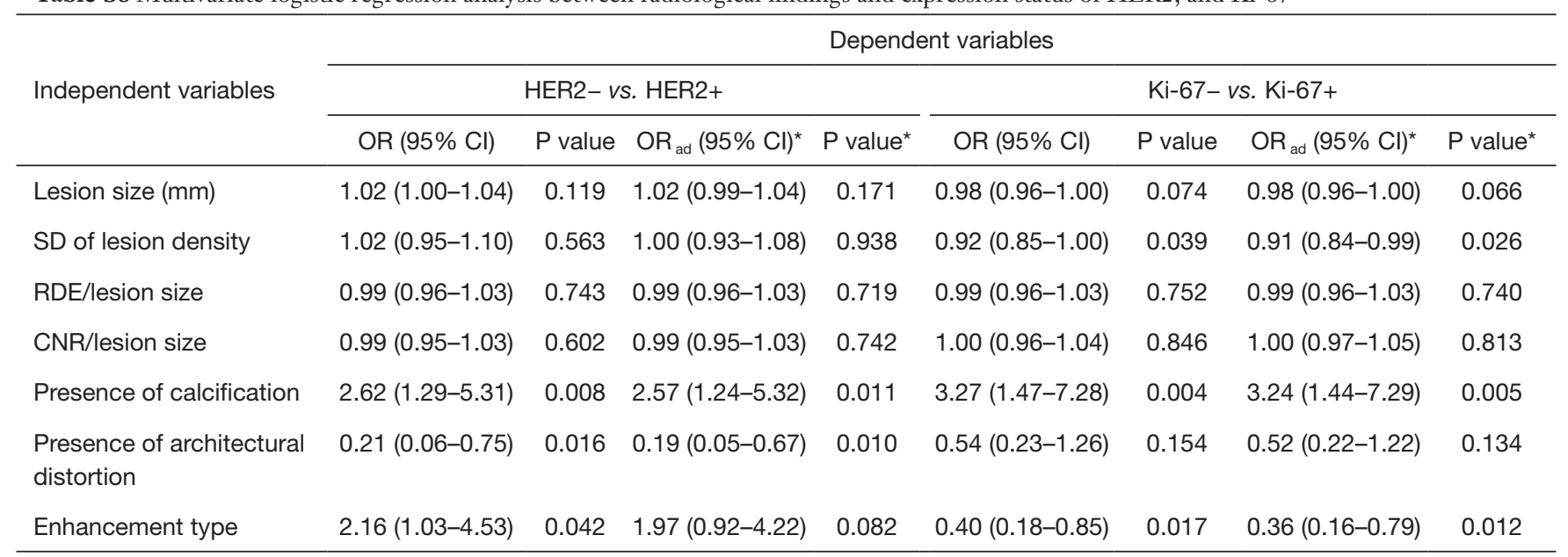

* The $\mathrm{ORs}_{\mathrm{ad}}$ and $\mathrm{P}$ values were adjusted for age, breast thickness and breast density; Cl, confidence interval; CNR, contrast-to-noise ratio; HER2, human epidermal growth factor receptor 2; OR, odds ratio; RDE, relative degree of enhancement; SD, standard deviation. 